\title{
Educational Resilience of Urban Squatter Children in Kathmandu
}

Indra Mani Rai*, Bal Chandra Luitel, Suresh Gautam, Binod Prasad Pant, and Santosh Gautam

School of Education, Kathmandu University, Lalitpur, Nepal

\begin{abstract}
Squatters are the illegal tenants residing in public lands as immigrants due to livelihood collapse in their origins. They have been denied of public resources and urban facilities because of their identity crisis leading to a vicious circle of poverty with impoverished livelihood creating multifaceted adversities of learning for their children. In this context, this paper, based on a cyclical mixed method research design under transformative research approach, has explored the learning adversities faced by the squatter children of Kathmandu Metropolitan city, their protective and promotive strategies to cope with adversities and life-skills as learning outcomes. Squatter children are struggling against the backdrop of exposure to unhygienic settlements with low health conditions, poverty with impoverished livelihood, and illiteracy of parents, poor homely environment, and dysfunctional families. Despite such adversities, they were able to continue school education with the support of their teachers, peers, parents and families. The research study finds stronger family and community assets of the students. These assets are helpful for building educational resilience of the squatter children.
\end{abstract}

Keywords: squatter, adversities, protective, promotive, life-skills 


\section{Background}

Nepal has become a partner in making international commitment of ensuring the right to quality education for all by 2015 . However, the access to quality education to the children of economically deprived communities like squatters of Kathmandu Metropolitan city is still unwelcoming. Only one Metropolitan city- 'Kathmandu' in Nepal is a prime inhabitation of squatters who are unlawful tenants or literally landless people (Tanaka, 2009). They are residing in public lands especially in the bank of Bagmati and Bishnumati rivers as immigrants either due to their livelihood collapse in their origins and displacement by natural disasters or conflict. They are deprived of public services and resources leading to poverty with impoverished livelihoods without adequate basic facilities of life (Shrestha, 2013). Further, about one fourth of the total squatters of the city are illiterate and a majority of them are barely literate with primary education (Shrestha, 2013).

The squatters have been suffering from inadequate food and longer hours of physical work and using their limited earning to "save the life of an ill family members and to feed their children" (Sharma, 2010, p. 187). Most squatters have been residing mostly on the river banks or in open spaces with "poor quality of houses" with no basic facilities of "pure drinking water, safe electricity, and drainage" which have become the cause of "poor educational achievements of their children" (Sharma, 2010, p. 190). It is evident that the squatter children have been facing multiple adversities of violence, abuses, and exploitation in the communities (Shrestha, 2013). These adverse conditions are unlikely to facilitate the learning of their children at homes and in the communities.

In this context, the major focus of the paper is to demonstrate the educational resilience of squatter children under the existing adversities. Specifically, this paper concentrates more on analysing adversities being facing by the squatter children in their learning context (communities and homes), protective and promotive factors, and life-skills as their learning outcomes. In doing so, we have organized the paper in different sections beginning with conceptualization of resilience followed by the methodology employed for the study. The paper progresses dealing with learning adversities, the protective and promotive factors they adopted/had to cope with the adversities and the life-skills they achieved as learning outcomes. Finally, we conclude the paper with our final insights. 


\section{Conceptualizing Educational Resilience}

The notion of resilience consists of two key components of exposing to "significant stressors or risks, and demonstration of competence and successful adaptation" (Braverman, 2001, p. 12). Thus it is the manifestation of positive adaptation of adversities/risks in one's socio-cultural context (Robertson-Hickling, Paisley, Guzder, \& Hickling, 2009). Specifically, educational resilience refers to "students who despite economic, cultural, and social barriers still succeed at high levels" (Robertson-Hickling et al., 2009, p. 5). Further, educational resilience as a construct asserts that children are under adverse situations and they navigate for resources (Ungar, 2012) themselves or with the support of external entities to cope or adapt the conditions with positive outcomes.

Adversities are the "exposure to environmental hazards, limited access to health care, socioeconomic disadvantages, family conflict, and economic stresses on the family" (Braverman, 2001, p. 5) as the barriers of children's learning. There are two forms of protective factors namely internal and external that the children use to protect themselves from adversities. The internal protective factors are the personal and social characteristics of children, responsiveness to people, communication skills, and desire to improve self (Werner \& Smith, 1993). The external protective factors on the other hand are the sources of support and structure in the child's environment such as parental warmth, emotional support, peer relationships, household rules, and access to services (Werner \& Smith, 1993). These internal and external protective factors serve as assets which are individual and environmental factors that facilitate to achieve positive outcomes (Braverman, 2001). The internal protective factors are the personal skills and psychological aspects and the external factors are the support of others including assets one possesses. Thus, in this research, we have attempted to explore what life-skills the squatter children have achieved through navigating these assets.

Families or family environments can serve as external 'protective factors' for children to achieve educational outcomes. Well-functioning families, that discipline their children, engage in meaningful communication and create a sense of family cohesion (Noltemeyer \& Bush, 2013), serve as pertinent protective factors for coping the risks. In addition, family cohesion and adaptability, effective parental communication skills, stable marital/couple relationships, and responsive, nurturing, and consistent firm parenting practices generally serve as protective factors for children (Noltemeyer \& Bush, 2013). Moreover, individual members of 
52 I. M. Rai, B. C. Luitel, Suresh Gautam, B. P. Pant \& Santosh Gautam

the families are able to navigate the resources to support for themselves and their children (Ungar, 2011). Likewise, caring teachers and peers can also contribute to the positive adjustment of children who are facing adversities. Therefore, warm and supportive teacher-student relationships also serve as protective factors (Noltemeyer \& Bush, 2013).

Communities can also serve as protective factors for children. Community resilience refers to the extent to which various forms of capital are available to residents of a community in general and to the children in particular. The children living in particular communities can have access to human capital (knowledge/ education), social capital (support networks, sense of community), natural capital (water, land), and physical capital (adequate/safe drinking water, roads) (Noltemeyer \& Bush, 2013; Ungar, 2011). Access to these types of assets serves to promote resilience on the part of the children. We have attempted to visualize the resilience among squatter children as developmental outcomes. It includes the development of positive cognitive, emotional and behavioral skills in spite of adversity. It is against this backdrop, we explored the promotive factors that allow children in urban squatter settlements to develop resilience such as optimism, tolerance, problem solving, sociability and flexibility (Reyes, 2013). When the asset is present, there is greater probability of successful developmental outcomes.

\section{Methodology}

We used qualitative dominant mixed method research approach under transformative research paradigm (Mertens, 2010) to capture the social complexity of educational resilience of squatter children. We purposefully selected two river bank squatter settlements (Bishnumati and Dhobikhola) of Kathmandu Metropolitan city. The mixed method research facilitated us to adopt multiple data collection methods such as survey, open interviews, Focus Group Discussions (FGDs) and observation (Mertens, 2010). We conducted a survey in 306 households of Bishnumati and 271 households of Dhobikhola to identify the demographic features of squatters and the types of schools their children were studying. In doing so, we identified 309 children responding our survey. We interviewed 20 children to explore the risk experiences. Further, we conducted five Focus Group Discussions (FGDs) (two in Bishnumati and three in Dhobikhola) to understand the collective views of squatters on the adversities faced by their children in their learning. In addition, we observed the behavior of squatter children and squatter people to understand the phenomena of resilience in a comprehensive manner. 
We developed questionnaires to capture the quantitative information of adversities the squatter children were facing and coping strategies they were adopting based on different literatures and discussing among the research team. Further, we developed guidelines of interviews and FGDs including possible themes of inquiry with a view to facilitate our research participants. We trained the enumerators for quantitative data collection whereas we, the researchers, were involved in making qualitative inquiries. We believed that the involvement of the researchers themselves in the field could help to be reflexive and to maintain the rigour of our research. Further, we maintained field notes and reflective journals or memos of the field. Similarly, we also maintained photographs of the field and recordings of the interactions.

We managed the numeric data by means of editing, coding, and decoding manually. We used the Statistical Package for Social Science (SPSS) programme to analyse the quantitative data. Then the data were tabulated and presented using descriptive statistics. We interpreted that results generated from the SPSS attaching meaning to specific numerical outputs. Further, we transcribed the interviews and FGDs (Lloyd-Evans, 2006) with the help of field notes and recordings. Then, we employed a sequential process of coding, categorizing, and thematising (Creswell, 2012) to analyze the qualitative data. After analysing both quantitative and qualitative data, we interpreted the realities of adversities and coping strategies deriving meaning.

As the notion of transformative research paradigm, we attempted to make heard the educational resilience of squatter children to multiple layers of stakeholders (children, teachers, parents, and community people) by going back to schools and communities and sharing the findings (Mertens, 2010). Our multiple engagements in the field helped us to reduce any possible bias and to get broader community support. Moreover, these 'going backs' were also helpful to check the interpretation we made (Mertens, 2010). This was also an approach of informing them the human rights violation of squatter people and their children. Further, we shared our findings in a national level conference in the presence of policy level stakeholders. This was an approach of policy advocacy to draw their attention to reform the policy, programmes, and plans in relation to the education of squatter children. 
54 I. M. Rai, B. C. Luitel, Suresh Gautam, B. P. Pant \& Santosh Gautam

\section{Adversities Faced by Squatter Children}

This section deals with the adversities faced by squatter children in their communities and families. In doing so, we have concentrated on environmental, socio-economic, and psychological risks as the hindering factors in their learning.

\section{Unhygienic Settlements and Suffering From Diseases}

As per our observation, the squatter settlement was unhygienic with poorly managed sanitation. The foul smell of polluted water collected as the discharge of urban settlements contributed to making air more polluted. We observed that there were dumping sites very close to most of the squatter settlements. One of the participants expressed, "The children often fall sick as there is a dumping site very close to this settlement. The people here do not manage their wastes properly." Because of this unhygienic environment and unmanaged sanitation, the squatter children were facing severe and frequent diseases. We found that almost all children $(83.3 \%)$ were reporting that they experienced sickness time and again.

In overall, $66 \%$ of the children expressed to have experienced injuries and casualties at their homes. As per our observation, the squatter children were playing with the dust and mud and the parents seemed irresponsible towards them. They seemed to be susceptible to different diseases, casualties and injuries as there was free mobility of children anywhere they liked. This was probably because many of them had less access to health counseling in the community. This situation showed the limited health care with low motivation and ability to learning of squatter children (Basch, 2010) which might be one of the adversities to create unfavourable situation for them to be motivated to learning. It may affect their ability of learning as they mostly remained absent from frequent illness and infection (Harker, 2006).

When we reached the research site, we could observe that the squatter children were playing with dust and mud. Possibly, their parents might have gone to labour work. There was no one who guided and instructed them to stay at home and study. The role of families as nurturers or supporters and parents' role of providing health safety and security (Boethel, 2004) were weaker. But the parents in Kathmandu squatter might not get sufficient time to take care of their children as they had to get engaged mostly in daily wages work. If parents looked around their children, they would not get enough food to have in the evening. When parents could not give time to take care of their children, the children were inevitably exposed to the unhealthy environment and got suffered from various diseases and became irregular to school. 
Possibly, parents were not aware of the health hazards faced by squatter children. Perhaps, they could not know how to protect their children from such risks. We also observed that many parents neglected their children when they were playing in the dust and mud. After having conversations with the parents, it occurred to us that many parents were unaware of the possibilities of different diseases when their children play in the dirt. Some parents told that their children do not obey them though the children were frequently warned not to play in such places. Those parents who were busy in their household jobs did not find time to look after their children after/before their school time.

\section{Parents' Education: Unhelpful to Children's Learning at Homes}

Most of the squatter people were illiterate. They were unable to support their children in learning at homes by providing quality time because of their longer hours of engagement in works. One of the FGD participants perceived, "Most of the parents are illiterate. Most of them have been depending on wage labour. There is nobody who can help children in their learning at homes." We understood that the squatter children were less cared by their parents in learning at homes. The involvement of families in the learning of children could enhance the performance of children (Boethel, 2004). But the illiterate parents were unlikely to support their children in doing homework or in learning at homes. Thus the less parental care towards enhancing the learning of squatter children was one of the key adversities for them. We understood that it was difficult for parents to establish an at-home learning environment for their children, encouraging learning, providing opportunities for learning (Henderson \& Orozco, 2003, as cited in Boethel, 2004). Further, we knew that the illiteracy of squatter people had led them to poverty with impoverished livelihoods.

\section{Impoverished Livelihood and Education of Children}

We realized that the impoverished livelihood of squatter people was one of the key hurdles of maintaining learning environment for their children. Most of the parents were engaged in wage labour followed by grocery shops, foreign wage labour, driving, and government services and private offices. A majority (58.7\%) of mothers were housewives and a few of them were small grocery shopkeepers and wage labourers too. One of the participants expressed,

I have five grandchildren. The elder one is in grade VII. He is irregular to school because I cannot send him to school without food. 
56 I. M. Rai, B. C. Luitel, Suresh Gautam, B. P. Pant \& Santosh Gautam

It is difficult to feed them. We cannot prepare food on time because we go to work in the morning, these children do not go to school. If we have food, we can send the children to school.

It was evident from the conversation that the residents were experiencing numerous hardships in life and were struggling for fulfilling the minimum living conditions.

Despite their low income, most of the squatter children (87.4\%) were attending schools whereas some (12.6\%) of them were not going to school. A large majority (59\%) of the children were not going to school due to the poor economic condition. Despite their low earning occupations, $60 \%$ of the children were studying in private/institutional schools with higher educational expenditure. Only one fourth (25\%) of squatter children were studying in public/community schools. But majority of children were not facing scarcity of educational expenditure. This was because many of them have been supported by the donors for their school expenditure including their uniforms and books, and stationeries.

Overall, a majority (53\%) of the children were facing lack of learning materials and $45 \%$ of them were facing lack of tiffin at home. Despite the donors' support, the squatter children were facing the scarcity of learning needs such as adequate tiffin and other learning materials at homes. This adversity of low family income may have led to underperformance as low income appears to be more strongly related to children's ability and achievement (Brooks-Gunn \& Duncan, 1997). The low earning was clearly visible in the housing conditions of squatter people.

\section{Unfavourable Home Environment}

As per our observation, we noticed the miserable home environment for learning. Congested and unmanaged settlement with unhygienic looking small huts was outwardly visible. The physical infrastructure of their homes looked to be in miserable condition. The narrow rooms and poor condition of the required gadgets were vividly reflecting the harsh realities at homes. In most of the houses, there were small common rooms for sleeping and cooking. In some houses, old tinned roofs allowed rainwater in. The huts were not enough to meet the minimum requirement of living. The small and generally single roomed huts were unlikely to serve as favorable environment at homes for the children to study. Some huts seemed more severe in conditions. We observed that these huts fenced with 
stitched sacks/clothes could not protect them from heat and cold. We sensed that these living conditions had created an unfavourable home environment for learning. Thus bad housing conditions were likely to affect children's ability to learn and study at home (Harker, 2006). This adversity of economic stresses has led some families to be dysfunctional.

\section{Dysfunctional Family}

During our field work, we observed that there were less family cohesion and harmony among the members of many squatter families and hence they were less functional. In this regard, one of the girls studying in Grade IX shared her experience, "Sometimes, my parents quarrel with each other mostly about money matter. Sometimes my father drinks much. I cannot study in this situation." We understood that the low income leading to hardships in living was the major causes of family conflict. The poverty leading to parents' conflict due to lack of money was another hurdle for them to learning at homes.

Some squatter children were facing such family conflict with multiplier effect of less concentration in study. There was a major "stress derailing the functioning of a family system, with ripple effects for all members" (Walsh, 2012, p. 175) including children. Further, the "socioeconomic backgrounds, parents' emotional well-being, positive inter-parental relations, and consistent parental support facilitate children's well-being" (Demo \& Cox, 2000, as cited in Boethel, 2004, p. 23). However, the dysfunctional families with conflicts and less cohesion among family members were likely to hinder children's emotional well-being and learning.

\section{Lack of Love and Care at Home}

When we walked in the squatter settlements to and fro, we observed many squatter children playing with dust and mud. We saw many children dirty as they were not given a bath for months. Nobody was caring them. The parents seemed less responsible about this matter. However, the children seemed happy playing in groups. We reckoned that they are habituated to play such rough and non-ruled games in such polluted environment. Owing to the low living standard and lack of awareness among the parents, the children seemed to be susceptible to different diseases. Moreover, there was free mobility of children. This showed high risks for children to be get into road accidents. The role of families as nurturers and supporters was found weaker in the case of squatter children. "The family's most basic role is to provide for their children's health, safety, security, and emotional 
58 I. M. Rai, B. C. Luitel, Suresh Gautam, B. P. Pant \& Santosh Gautam

well-being" (Boethel, 2004, p. 15). We noticed less close and dependable relationships that provided love and nurturance, security, responsive interaction, and encouragement for exploration (Boethel, 2004).

Therefore, the unhygienic settlement with poorly managed sanitation was likely to lead the squatter children to suffer from frequent diseases and in turn face adversity in their learning. Furthermore, the impoverished livelihood with poorly managed homely infrastructure was less supportive to their children's learning. Insecurity of livelihood has further led to limited access to health care and economic stresses on the family to family conflict (Braverman, 2001). Many illiterate squatter people were unlikely to interact and support meaningfully to their children at homes. In some cases, there were less cohesive families impeding to their learning. These risks were likely to affect the squatter children "cognitively, emotionally and behaviorally across all stages of the development" (Reyes, 2013, p. 15).

\section{Protective and Promotive Factors}

To cope with these adversities, in this section, we discuss some key protective and promotive factors. We understood that the schools, families, and communities were the key to protect and promote them against the adversities.

\section{Supportive Teachers and Peers}

The teachers and peers come into regular interaction with children in their learning context. A large majority (52.7\%) of children reported that the teachers were supportive. We understood that the teachers and peers were more caring, loving, co-operative, and responsive to squatter children. In this regard, one of the students expressed.

When I don't have pencil or copy the teachers or friends provide me.

When I suffer from headache or get injured they treat me and give me medicine. Teachers and friends are helpful in every hardship.

It made us realize that the squatter children were experiencing the support of teachers and friends at the time of sickness and scarcity of learning materials. This also indicated that the squatter children had amiable relationships with the teachers and peers. Almost all the participants said that they felt lonely, monotonous and bored at their homes and this monotony and boredom could be easily overcome being amidst the teachers and friends at school and in the community. This was because the majority of children did not have to experience 
being laughed at, teased, discriminated, and undermined by their friends and teachers. This was another driving force enabling the children to grow amidst adversities.

We also came to know that the teachers and peers were encouraging and motivating for pursuing their learning. We realized that there was a culture of appreciating the attempts of positive learning activities, which has worked as reinforcement to the children in their learning endeavours. This helped them to overcome the adversities and foster their learning. One of the students studying in Grade VIII shared his experience this way, "Yes, my friends as well as my teachers praise me when I perform well in study. They encourage me all the time in extra activities. "It seemed to us that the appreciation and praise of teachers and friends served as a motivating factor for the squatter children to cope with hardships and emerging problems. This culture was instrumental in solving their multifarious problems in learning.

We understood that the teachers, sometimes, scolded them with a view to track them in right disciplinary and learning directions. Thus, maximum children were afraid of teachers if they did not do homework. A majority (38.5\%) of children were in favour of doing homework to cope with the fear of teachers. A large majority of children (52\%) did their home assignments regularly and some of them (21\%) did not want to make mistakes. Therefore, the teachers' scolding as a corrective measure was a key protective factor for the squatter children to be in the learning process. Thus, it seemed to us that the schools were providing "a critical context in shaping children's self-efficacy and sense of control over their lives" (Childhelp, 2011, What Schools Can Do to Promote Protective Factors? para. 1). In addition to this, we noticed that certain families were also serving as protective and promotive factors.

\section{Supportive Role of Families}

As discussed earlier, there were many parents who were less caring and responsible to their children. However, in some cases, the squatter families were supportive to and caring for their children's education. As per the experience from the FGDs, there were no physical punishments from their parents to the children except occasional minor scolding with a view to tracking the children's behavior in a positive direction. In this regard, one of the girls shared, "I get scolded when I don't read and quarrel with my brothers or sisters. My parents scold me when I play longer with the friends and when I don't do household chores. But my 
60 I. M. Rai, B. C. Luitel, Suresh Gautam, B. P. Pant \& Santosh Gautam

parents do not beat me." We got an insight that the parents' occasional suggestive scolding was to modify the learning behaviors of their children. We realized that this mode of suggestive scolding was the demonstration of attention of parents towards their children rather than bullying or enforcing violence against them.

A majority (53.3\%) of children faced such scolding from their parents. To cope with the parents' scolding, a maximum of them (38.3\%) helped parents in household chores and some of them adopted diverse strategies of lessening the frequency to go out to friends' house, focusing on study, lessening television watching hours. Likewise, many of them (31.2\%) wanted to be sincere for not making mistakes. Some of them (20\%) studied well, and a few of them were in favour of lessening play hours. We realized that the scolding from the parents was a corrective measure for the squatter children to develop their positive behaviors. The parents' attentiveness towards their children's overall development was one of the key protective factors to avoid adversities of the squatter children.

On the other hand, under hardships of living they were giving foremost emphasis to the education of their children. We sensed that the parents were committed and dedicated toeducating their children. In this regard, one of the parents opined, "Sir, we don't want him to be like us. If he studies well he will surely find a better job for a happy living. We are ready to have one meal a day but we will educate him." This shows the determination of squatter people to educating their children. The parents' sensitivity, awareness of value education, and their prioritized efforts to providing education to their children were supportive to the learning of squatter children. We noticed that the squatter families were under the "stresses of uncertainties of economic, social, and environmental upheavals" (Walsh, 2012, p. 175). However, they were giving first preference to the education of their children.

We realized that they have been demonstrating their determination of securing better future for their children by supporting them at the highest extent of their resources. In this regard, a high majority (61.2\%) of children reported that they were supported by their parents in their study. In case of scarcity of learning materials, most of the squatter children $(83.3 \%)$ were asking their parents to support for learning materials. Large majorities $(63 \%)$ of them were not hesitant to speak with their parents and maximum (45\%) children were very unlikely to have fear with parents. This showed that the children were more cohesive with their parents. The parental engagement in children's learning was likely to contribute to 
the educational performance (Grant, 2009). Thus the positive relationships among the family members and their support helped the squatter children to cope with the exposure to adversities with negative outcomes (Zimmerman et al., 2013).

\section{Role of Community and Government Structures}

There were a number of community and government structures working for enhancing the learning of squatter children. School Management Committees (SMCs) were one of the government structures which have been supporting to create conducive learning environment for squatter children. One female participant shared her experiences.

Every year we launch an enrolment campaign in the squatter and encourage all the parents to send their children to school. We also waive the admission fee for the children of downtrodden families.

The active involvement of community people through SMCs to ensuring the right to education of the squatter children was a pertinent protective measure of their learning. We realized that they were encouraging and helping the helpless children for their schooling bearing their school expenditure. This self-guided collective social effort of squatter people was promotive to enhancing the learning of squatter children.

As per our observation, there were tuition centers run by either college going students or religious organization (Church) for the squatter children which were platforms for them to engage in learning under the guidance of local teachers. We came to know that the centers were supportive to illiterate parents to fulfill the learning needs of their children. Likewise, a religious organization (Church) was another community structure which was supporting to meet the educational expenditure. Furthermore, there was one community club in each squatter area established to develop games and sports of local children. We understood that the clubs were likely to have been contributing to the physical, mental, and emotional development of certain children who participated in the club activities. In addition, there were a number of cooperatives with regular deposits and loan flow. We realized that these types of financial networks were contributing to enhancing the livelihood of squatter people to some extent so that they could make a minimum level of expenditure on their children's education.

As per our observation, there were no health posts and hospitals in the settlement area as such. We noticed that there were small clinics and pharmacies. 
62 I. M. Rai, B. C. Luitel, Suresh Gautam, B. P. Pant \& Santosh Gautam

We sensed that these were basically providing first aid treatment in case of injuries and casualties. Our numerical information suggested that maximum (45\%) children were in favour of being careful about injuries followed by the children who wanted to go to medical centers or hospitals (38\%) in case of injuries and minimum (16.6\%) reported to rely on first aid. Further, some of them $(23 \%)$ were in support of having healthy food. Overall, most of the children (83.3\%) were going to hospital for healing ailments. These clinics and pharmacies were playing the protective roles in case of those who needed immediate health care and support.

We viewed that these community structures were the assets for the resilience of squatter children. We realized that they have been developing the physical assets like community clubs and social capitals/networks among them to cope with the adversities (Ungar, 2012). Moreover, "a better educated and cohesive community is more likely to be an effective advocate for improved public services" (Ungar, 2011, p. 1745). The participation of community people through diverse social structures has integrated the assets and resources for promoting their children's development. We came to know that these structures were likely to "offer opportunities to explore areas of interest, acquire skills, develop talents, and experience success" (Zimmerman et al., 2013, p. 217). We understood that the assets that they have accumulated served to positive learning outcomes.

Therefore, the amiable and supportive teachers and peers at the time of hardships and culture of praise and appreciation for the positive works of squatter children have motivated and encouraged them towards learning. These cohesion and harmony among peers and with the teachers have played the protective and promotive role for children with developmental vulnerabilities (Noltemeyer \& Bush, 2013). Further, squatter families were attentive and supportive to modify them in positive learning behaviours and were providing minimum educational expenditure under hardships of living. Certain squatter families were maintaining control over their children and providing meaningful communication with their children (Noltemeyer \& Bush, 2013). In some cases, there were cohesive families with interactive and communicative members and these consistent parenting practices generally served as protective factors for squatter children (Noltemeyer $\&$ Bush, 2013). In addition, the community structures like SMCs, religious donor organizations, tuition centers and clubs were the assets for the educational resilience of squatter children. The other community structures like health centers and cooperatives were promotive assets which were accessible resources (social 
capitals) which supported for the resiliency of themselves (Ungar, 2012).

\section{Life Skills Achieved as Learning Outcomes}

It is our realization that the protective and promotive factors of learning adversities discussed earlier have given rise to some key life-skills as developmental outcomes of squatter children.

\section{Courage to Be Prospective Professionals}

We realized that most of the squatter children had specific ambition in life which they thought would be fulfilled through education. We came to know that they have developed a perception of being prospective professionals. Moreover, they had been tamed to be hopeful to acquire a better status through education and to support their parents in the future. Moti opined:

My aim is to be a doctor. My parents and teachers encourage me to be a great person. I am working hard to be a great person.

This optimism showed the positive attitude of the squatter children. "It seems obvious that a positive outlook on life is an important part of resiliency" (Hoffman, 2012, p. 14). Setting the goal or aim to be a prospective professional in the future was a motivating factor for them in learning. This has led them to be more hardworking and devoted to learning. It also showed that they have got "better sense of rising importance of learning and education in their lives" (Trilling \& Fabel, 2009, p. 11).

\section{Realization of Self Roles: Towards Self-Reliance}

We understood that the squatter children have realized their social and household roles. They also perceived themselves to be the members of the family and the larger community. Moreover, the attempt of the parents and teachers to make them self-reliant and well prepared for life was reflected in the views of Mohan who expressed,

When I am free I help my parents in their work. As they give me responsibilities I have learnt to do many things independently. Parents ask me to manage my things, wash my clothes, and take care of my brother. Now I don't have difficulty in doing such works.

This showed that the values of life, ethics and cultural norms have been inculcated in the children. As a result, they were in track of realization of their social roles. 
64 I. M. Rai, B. C. Luitel, Suresh Gautam, B. P. Pant \& Santosh Gautam

In spite of having faced multifarious hardships, the parents have endeavoured to keep the spirit of the children high and to make them self-reliant through continuous attempts to train them about the practical requirements of life and through counseling for better future. Bearing responsibilities of different household works demonstrated the sharing of hardships of life. This showed that they have been educated to pave a path for the future by making them acquainted with different facets of life and by developing their self-reliance. They were developing "deeper levels of initiative and self-direction skills with an appropriate level of freedom to exercise self-direction and initiative" (Trilling \& Fabel, 2009, p. 78).

\section{Social and Cross-Cultural Interaction}

As per our interaction with the squatter children, we knew that they were interacting among themselves from diverse backgrounds in terms of caste or ethnicity, economic and social status. They were maintaining social cohesion and harmony among them. They had no sense of discrimination. Sumiki, from a low caste family, as had been called in the community, had no feeling of being discriminated. She expressed,

I don't believe in discrimination based on castelethnicity. Low or high castes/ethnicities are created by the people. All human beings are equal as all of them have the same red blood. We are equally involved in all social activities and class activities.

In spite of being the residents of squatter, the children were found to have no feeling of hierarchies and discrimination. They did not think themselves to be different from the children of higher or lower class families. They have developed interactive practices among peers from different cultural and economic groups.

They were aware that the caste/ethnicity based hierarchies have been created socially and hence they were in position of contesting such stereotypic thinking and behaviors. They were found to have developed an essential life skill of working with team members and classmates regardless of differences in culture and class (Trilling \& Fabel, 2009). This tradition of "understanding and accommodating cultural and social differences was likely to come up with even more creative ideas and solutions to problems" (Trilling \& Fabel, 2009, p. 50).

\section{Towards Developing Innovative Skills}

During our field work, we found that many squatter children were full of 
enthusiasm, zeal, and excitement towards learning. They were confident and outspoken. Arjun experienced,

There is a library in the school. I often borrow books from the library and read at home. Generally, I read stories and poems. I ask questions to the teachers if I don't understand in the class. We discuss and share with each other what we know or don't know.

The squatter children wanted to learn something new from teachers and from any other sources including library readings. We realized that some of the children were more inquisitive. The children were more discursive and interactive in their learning activities sharing the ideas or knowledge with each other.

The learning enthusiasm of squatter children was likely to foster more independent quality learning in their socio-cultural setting. Thus, certain squatter children were in track of developing study culture being more exploratory and independent. They have acquired "one of the life skills of being towards innovative in learning which has long been at the heart of what it takes to become a self-reliant lifelong learner" (Trilling \& Fabel, 2009, p. 49). They have developed "the ability to ask and answer important questions, to pose and solve problems, to communicate and work with others in learning, and to create new knowledge and innovations" (Trilling \& Fadel, 2009, p. 49).

Therefore, the squatter children were optimistic of being prospective professionals which was a motivating factor of learning. Furthermore, they were developing the sense of their roles and responsibilities in their social context towards self-reliance habits. They were developing the interactive and exploratory learning habits within the context of diverse learners. Thus, the squatter children were developing skills to adjust in complex social structures of modern age (Trilling \& Fadel, 2009).

\section{Conclusion: Building Resilience}

Squatter children are facing multifaceted nature of adversities that are impeding their learning mostly in their community and home environment. They are within the interwoven adversities of exposure of unhygienic community environment with poorly managed sanitation causing diseases and infections. Education of parents is unhelpful to make their children engaged in learning at homes meaningfully. They are in poverty stricken families with impoverished livelihood with low living conditions creating barriers to them in learning at 
66 I. M. Rai, B. C. Luitel, Suresh Gautam, B. P. Pant \& Santosh Gautam

homes. The low income creates stresses among the family members leading the families to be dysfunctional which in turn creates an unfavorable learning environment at homes for the children.

The squatter children are wrestling with these learning adversities in their context. Nevertheless, they are achieving resilience in the presence of protective and promotive factors in schools, families, and communities. Amiable teachers and peers and their praise and appreciations are motivating them towards learning. Furthermore, the attention of family members and their determination under hardships of living to providing their children with necessary educational support are the promotive measures for the children in adversities of learning. The community and government structures are serving as social assets that are creating opportunities for promoting learning to the squatter children.

As a consequence of educational resilience, an optimistic sense of being prospective professionals developed in the children serves as a motivational factor for further learning. The resiliency is promoting the realization of household responsibilities of children leading towards self-reliance. The squatter children are adopting non-discriminatory interaction among the people from diverse cultural and economic backgrounds. This socialization skill is an important life-skill of the squatter children. Moreover, through the protective and promotive assets of children, they are developing exploratory learning habits towards being selfreliant and independent learners.

\section{References}

Basch, C. E. (2010). Healthier students are better learners: A missing link in school reforms to close the achievement gap (Research Review No. 6). New York, NY: Teachers College, Columbia University.

Brooks-Gunn, J., \& Duncan, G. J. (1997). The effects of poverty on children. The Future of Children, 7(2), 55-71.

Braverman, M. T. (2001). Applying resilience theory to the prevention of adolescent substance abuse. FOCUS. Retrieved from http://4h.ucanr.edu/ files/1232.pdf

Boethel, M. (2004). Readiness: School, family, and community connections. Austin, TX: National Center for Family and Community Connections with Schools.

Creswell, J. W. (2012). Educational research: Planning, conducting, and 
evaluating quantitative and qualitative research (4th ed.). Boston, MA: Pearson Education.

Childhelp. (2011). Risk and protective factors: What schools can do to build protective factors. Retrieved from www.childhelp.org/SpeakUpBeSafe

Grant, L. (2009). Children's role in home-school relationships and the role of digital technologies: A literature review. Bristol, England: Futurelab Innovation in Education.

Hoffman, J. (2012). Parenting resilient children at home and at school. Quebec City, Canada: Desjardins Financial Security.

Harker, L. (2006). Chance of a lifetime: The impact of bad housing on children's lives. London, England: Shelter.

Lloyd-Evans, S. (2006). Focus groups. In V. Desai \& R. B. Potter (Eds.), Doing development research (pp. 151-162). Thousand Oaks, CA: Sage.

Mertens, D. M. (2010). Philosophy of mixed methods teaching: The transformative paradigm as illustration. International Journal of Multiple Research Approaches, 4, 9-18.

Noltemeyer, A. L., \& Bush, K. R. (2013). Adversity and resilience: A synthesis of international research. School Psychology International, 34, 474. doi: $10.1177 / 0143034312472758$

Reyes, J. (2013). What matters most for students in contexts of adversity: A framework paper. Washington, DC: World Bank

Robertson-Hickling, H., Paisley, V., Guzder, J., \& Hickling, F. W. (2009). Fostering resilience in children at risk through a cultural therapy intervention in Kingston, Jamaica. Journal of Health Care for the Poor and Underserved, 20,31-35.

Sharma, B. R. (2010). Urban poverty: A sociological study of Shankhamul squatter. Dhaulagiri Journal of Sociology and Anthropology, 4, 179-192.

Shrestha, B. K. (2013). Squatter settlements in the Kathmandu valley: Looking through the prism of land rights and tenure security. Urban Forum, 24(1), 119-135. doi:10.1007/s12132-013-9189-x

Trilling, B., \& Fadel, C. (2009). 21st century skills: Learning for life in our times. San Francisco, CA: Jossey Bass. 
68 I. M. Rai, B. C. Luitel, Suresh Gautam, B. P. Pant \& Santosh Gautam

Tanaka, M. (2009). From confrontation to collaboration: A decade in the work of the squatters' movement in Nepal. Environment and Urbanization, 21(1), 143-159. doi:10.1177/0956247809103011

Ungar, M. (2011). Community resilience for youth and families: Facilitative physical and social capital in contexts of adversity. Children and Youth Services Review, 33, 1742-1748.

Ungar, M. (2012). Social ecologies and their contribution to resilience. In M. Ungar (Ed.), The social ecology of resilience: A handbook of theory and practice (pp. 13-31). New York, NY: Springer.

Werner, E. E., \& Smith, R. S. (1993). Overcoming the odds: High risk children from birth to adulthood. Ithaca, NY: Cornell University Press.

Walsh, F. (2012). Facilitating family resilience: Relational resources for positive youth development in conditions of adversity. In M. Ungar (Ed.), The social ecology of resilience: A handbook of theory and practice (pp. 173-185). New York, NY: Springer.

Zimmerman, M. A., Stoddard, S. A., Eisman, A. B., Caldwell, C. H., Aiyer, S. M., \& Miller, A. (2013). Adolescent resilience: Promotive factors that inform prevention. Child Development Perspectives, 7(4), 215-220. doi:10.1111/ cdep. 12042 